\title{
Recovery of Cardiovascular Function in Newborn Lambs after Thoracotomy
}

\author{
DANIEL SIDI, ${ }^{(9)}$ JAAP R.G. KUIPERS, ${ }^{(10)}$ MICHAEL A. HEYMANN, ${ }^{(12)}$ AND \\ ABRAHAM M. RUDOLPH \\ Cardiovascular Research Institute and the Departments of Pediatrics, Physiology, and Obstetrics, Gynecology, and \\ Reproductive Sciences, University of California, San Francisco, California, USA
}

\begin{abstract}
Summary
Knowledge of the quality and speed of recovery after thoracotomy is crucial for studies of the early changes in cardiovascular function in the neonatal period. We studied the early recovery period after thoracotomy with pericardiotomy, but without ventriculotomy, in 21 lambs operated on between 2-24 days after birth. In 15 lambs, we measured resting $\mathrm{pH}, \mathrm{PaO}_{2}, \mathrm{PaCO}_{2}, \mathrm{O}_{2}$ consumption, cardiac output, heart rate, and aortic and pulmonary arterial pressures, before and after thoracotomy, daily for 1 wk. We found that, except for $\mathrm{PaO}_{2}$ (82 versus 87 torr), all variables returned to normal by the third day after thoracotomy. Four lambs were exposed to hypoxia (FIO ${ }_{2} 0.09$ for $1 \mathrm{~h}$ ) before and 3 days after thoracotomy; hypoxia-induced changes were not different at the two different periods. Six other lambs, undergoing thoracotomy within the first 3 days after birth and exposed to hypoxia on the third postoperative day, had hypoxia-induced responses similar to six age-matched nonthoracotomized lambs. These findings indicate recovery of cardiovascular function by 48-72 b after thoracotomy. We believe, therefore, that reliable studies of the circulation in lambs are possible as early as 3-4 days after birth, even if thoracotomy is required for making measurements.
\end{abstract}

\section{Speculation}

Thoracotomy, often required for the study of cardiovascular function, has adverse effects for a certain period of time. In newborn and young animals this period is only 2-3 days, thereby permitting essentially uninterrupted longitudinal studies despite thoracotomy.

To measure specific cardiovascular functions in animals, thoracotomy often is needed to implant catheters, or for the placement of flow transducers. Cardiovascular and respiratory functions might be altered for some time and thereby interfere with long term physiologic measurements. In adults, one could wait for a long recovery period before studying the animals, however, this is not possible in the rapidly growing newborn where the objectives may be the evaluation of the changes after birth.

It is important, therefore, to know how quickly and completely the newborn animal recovers from thoracotomy. Daily studies will determine the recovery period required to avoid the effects of anesthesia and surgery. Study of the recovery period also should include responses to additional acute stress, because evaluation of values at rest alone may be misleading. On one hand, resting values could appear to be normal as a result of compensatory mechanisms; on the other, even if resting values are modified slightly, this does not necessarily imply that physiologic responses to stress may not be preserved. Therefore, we measured daily several cardiovascular (not including contractility indices) and hematologic variables, before and after thoracotomy, in lambs operated on as early as the second day after birth. We compared responses to hypoxia in a group of lambs before and shortly after thoracotomy. In another study we compared responses to hypoxia between a group of thoracotomized newborn lambs and an agematched group of unoperated lambs.

\section{MATERIALS AND METHODS}

\section{EXPERIMENTAL DESIGN}

We studied 27 lambs of mixed western breed. In all, the date of birth was documented. Three series of studies were performed.

I. Pre- and postthoracotomy resting values in the same lamb. In 18 lambs, catheters were inserted into cervical vessels and the animals allowed to recover. A thoracotomy was then performed between 5-24 days after birth. Measurements were made the day after implantation of the catheters, just before thoracotomy, every day after thoracotomy for 4 days and then every second day for 4 days. Three lambs died at or soon after thoracotomy before postoperative measurements were made. The 15 survivors had at least three postoperative measurements to compare with preoperative values.

II. Responses to hypoxia before and after thoracotomy in the same lamb. In four of the 15 surviving lambs of group I, the effects of hypoxia were studied 3 or 4 days before thoracotomy and on the third day after thoracotomy, performed 7-15 days after birth.

III. Responses to hypoxia in age-matched lambs with or without thoracotomy. In three of the four lambs of group II, plus another nine lambs, the effects of hypoxia were studied between 3-6 days after birth. In the three lambs from group II, used for this part of the analysis before they underwent thoracotomy, plus three of the additional nine, the hypoxia studies were performed on the day after neck catheters only had been inserted. In the six other lambs, we performed a thoracotomy and the lambs were studied on the third postoperative day, at ages equivalent to the nine animals who had had a thoracotomy.

\section{SURGICAL PROCEDURES}

Cervical vessel catheterization. Under local anesthesia with $0.5 \%$ lidocaine $\mathrm{HCl}$ (Xylocaine), catheters were inserted into a carotid artery and jugular vein and advanced to the ascending aorta and pulmonary artery, respectively, during which time pressure was monitored. We used polyvinyl catheters (O.D., $1.8 \mathrm{~mm}$ and I.D., $1.0 \mathrm{~mm}$ ) for the aorta, and either a polyvinyl catheter (O.D., 1.2 $\mathrm{mm}$ and I.D., $0.75 \mathrm{~mm}$ ), a 5F Swan-Ganz balloon catheter, or a 5F K.M.A. thermodilution catheter for the pulmonary artery.

Thoracotomy. Anesthesia was induced by inhalation of 2-3\% halothane. The lamb was intubated with a cuffed endotracheal tube, placed on a warming pad, and ventilated with $0.5-0.75 \%$ halothane in $100 \%$ oxygen by a positive pressure respiratory pump (Harvard Apparatus, MA). Inspiratory volume was $15 \mathrm{ml} / \mathrm{kg}$, the initial pump frequency was $15-20$ cycles/min and end-tidal pressure was $3-5 \mathrm{~cm} \mathrm{H}_{2} \mathrm{O}$. Stroke rate and inspiratory volume were adjusted before the chest was opened to maintain $\mathrm{PaCO}_{2}$ at $35-40$ torr and $\mathrm{pH}$ at 7.38-7.45.

Using sterile techniques, we performed a left thoracotomy in the third intercostal space in 12 lambs. Polyvinyl catheters (O.D., 
$1.2 \mathrm{~mm}$ and I.D., $0.75 \mathrm{~mm}$ ) were inserted into the internal thoracic artery and vein and advanced to the brachiocephalic trunk and superior vena cava, respectively. The pericardium was incised over the main pulmonary artery parallel to this vessel to within 2-3 $\mathrm{mm}$ of the sympathetic and vagus nerves. Polyvinyl catheters (O.D., $1.2 \mathrm{~mm}$ and I.D., $0.75 \mathrm{~mm}$ ) were inserted, through pursestring sutures, directly into the main pulmonary artery and through the left atrial appendage into the body of the left atrium. After connective tissue around the ascending aorta was removed, the diameter of the aorta was measured with calipers. A precalibrated electromagnetic flow transducer (C-C Instruments, I.D., 7-13 mm), selected to fit snugly without constriction, was applied around the aorta just above the coronary arteries. In another 12 lambs the thoracotomy was performed through the fourth intercostal space, and, in addition to the catheters and the flow transducer described above, we inserted a polyvinyl catheter (O.D., $1.8 \mathrm{~mm}$, and I.D., $1 \mathrm{~mm}$ ) into the coronary sinus (nine lambs) (1) or a polyvinyl catheter (O.D., $1.2 \mathrm{~mm}$ and I.D., 0.75 $\mathrm{mm}$ ) into a pulmonary vein (three lambs) in order to obtain blood samples for other studies. In all 24 lambs, a \#8F polyvinyl catheter was placed in the left pleural cavity and used as a chest drainage tube. No attempt was made to close the pericardium. All catheters were filled with heparin and led with the chest tube and the flow transducer cable to the left flank, where they were protected by a cloth pocket sewn to the skin. The chest was closed in layers.

During the procedure we paid special attention to maintaining the halothane concentration as low as possible, adjusting the ventilation by checking $\mathrm{pH}$ and $\mathrm{PaCO}_{2}$ repeatedly, and expanding the lungs by occluding the expiratory tube for three or four respiratory cycles every $20-30 \mathrm{~min}$. We replaced blood loss with adult blood only when this was estimated to exceed $20 \mathrm{ml}$, because we wanted to avoid altering the oxygen equilibration curve of the blood.

After the operation, we kept the lamb in a sling under a heating lamp and infused $10 \%$ dextrose intravenously at a rate of about 20 $\mathrm{ml} / \mathrm{h}$. When the lambs could stand and suck, we brought them back to their mothers; usually they fed immediately. Most lambs were returned to the ewe within 3-4 h; a few, however, were kept in the sling for as long as $12 \mathrm{~h}$. We flushed the catheters daily with $0.9 \%$ saline and filled them with heparin solution. Procaine penicillin, 100,000 U/kg, and dihydrostreptomycin, $50 \mathrm{mg} / \mathrm{kg}$, were given intramuscularly every day for 5 days.

\section{PROCEDURES}

Measurements. For each study the lamb was removed from the ewe, weighed, and placed in a sling so that it was supported in an upright position. The lamb was blindfolded so that it would be calm in the laboratory. A loosely fitting mask was placed over its face to collect mixed expired gas for continuous $\mathrm{O}_{2}$ consumption measurement by the flow-through system described previously (5). Aortic and pulmonary arterial blood pressures were measured with Statham P23Db pressure transducers and recorded continuously on a Beckman direct writing recorder. Heart rate was calculated from the aortic pressure tracing. Intermittent $1 \mathrm{ml}$ blood samples were obtained simultaneously from the aorta and pulmonary artery. Blood gas tensions and $\mathrm{pH}$, hemoglobin, and $\mathrm{O}_{2}$ saturation were measured with a Radiometer blood gas analyzer and a Radiometer OSM-2 Hemoximeter, respectively. $\mathrm{O}_{2}$ content was calculated from the product of $\mathrm{O}_{2}$ saturation, hemoglobin concentration and a hemoglobin binding capacity of $1.36(3,6)$. Cardiac output was calculated by the Fick equation (aortic and pulmonary arterial blood $\mathrm{O}_{2}$ content and $\mathrm{VO}_{2}$ ), which we have shown is accurate for measuring cardiac output in young lambs (4). Indocyanine green indicator dilution curves were performed and analyzed qualitatively for detection of right-to-left or left-toright shunts. Surface area was calculated from the weight (7) by applying the formula $0.124 \times \mathrm{kg}^{0.561}$. Cardiac output and $\mathrm{O}_{2}$ consumption were expressed not only in relationship to body weight, but also to surface area, in order to minimize the normal daily changes due to the rapid growth of the lambs during the first wk after birth. The lambs were not sedated and data were collected only when they were quiet and resting. Because ambient temperature influences $\mathrm{O}_{2}$ consumption and cardiovascular function at rest as well as during hypoxia (Sidi, unpublished data), we kept the ambient temperature at $25 \pm 0.5^{\circ} \mathrm{C}$ during all studies.

Hypoxia experiments. After control measurements were made while the lamb breathed room air, $9 \%$ oxygen in nitrogen, obtained from a gas mixer, was blown into a large plastic bag surrounding the head and neck and including the face mask described above for collection of expired air. The hypoxic gas was administered at a flow rate that greatly exceeded the minute ventilation of the lamb, so that room air could not be drawn into the face mask. Before each measurement of $\mathrm{O}_{2}$ consumption, the inspired fraction of $\mathrm{O}_{2}$ was checked on gas transferred from the gas mixer to the $\mathrm{O}_{2}$ analyzer. The inspired fraction of $\mathrm{O}_{2}$ varied less than $0.2 \%$ per $\mathrm{h}$ during hypoxia. $\mathrm{O}_{2}$ consumption, heart rate, and aortic and pulmonary arterial blood pressures were measured continuously; paired blood samples were withdrawn from the pulmonary artery and aorta at $15,30,45$, and $60 \mathrm{~min}$ after the onset of hypoxia. Before ending the hypoxia, an indicator dilution curve was obtained.

Analysis. Analysis of the effects of thoracotomy on $\mathrm{O}_{2}$ consumption, cardiac output, and heart rate is complicated by the normal change of these variables with advancing age and increasing body weight. We obtained data on the normal changes with age in the lambs we studied by fitting a linear regression line to all the values obtained before thoracotomy (5-24 days of age). We then compared, by analysis of covariance, this regression line (representing preoperative resting values) to the resting line calculated from values on the third (Fig. 1) and on the sixth postoperative days. This allowed the comparison of the normal sequential changes that occur with advancing age with those that
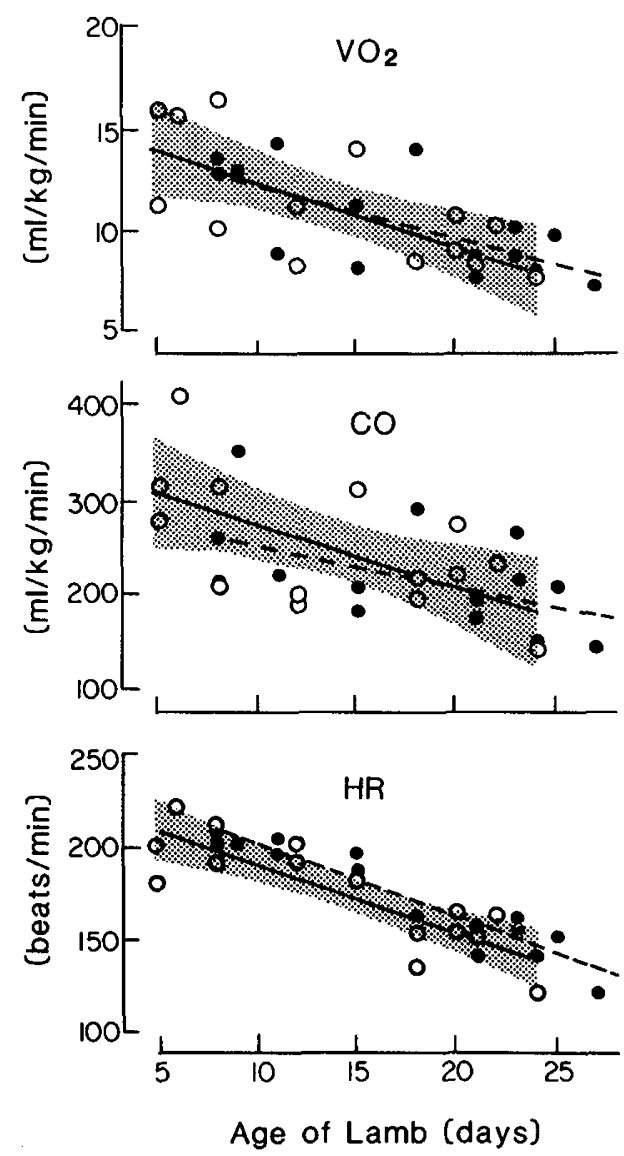

Fig. 1. Comparison of the changes with age of $\mathrm{O}_{2}$ consumption per min $\left(\mathrm{VO}_{2}\right)$, cardiac output $(\mathrm{CO})$, and heart rate $(\mathrm{HR})$ in 15 lambs before $(\mathrm{y})$ $\left(\mathrm{O}-\right.$ and on the third day after $\left(\mathrm{y}^{\prime}\right)$ thoracotomy $(--) . \mathrm{VO}_{2}: \mathrm{y}=$ $-0.307 x+15.45, y^{\prime}=-0.254 x+14.8 ; \mathrm{CO}: y=-6.35 x+336, y^{\prime}=-4.20 x$ +293 ; and HR: $y=-3.66 x+226, y^{\prime}=-3.95 x+239$. The gray area represents the $95 \%$ confidence limit for the line fitted to preoperative data. 
Table 1. Cardiovascular variables, oxygen consumption, $p H$, and blood gas values in resting lambs before and after thoracotomy (Group $I)^{1}$

Postthoracotomy (days)

\begin{tabular}{|c|c|c|c|c|c|c|c|}
\hline & \multirow{2}{*}{$\begin{array}{c}\text { Pre- } \\
\text { thoracotomy }\end{array}$} & \\
\hline & & +1 & +2 & +3 & +4 & +6 & +8 \\
\hline Number & 15 & 15 & 15 & 15 & 14 & 14 & 13 \\
\hline Weight (kg) & $6.8 \pm 2.6$ & $6.7 \pm 2.6$ & $7.0 \pm 2.5$ & $7.5 \pm 2.4$ & $7.55 \pm 2.4$ & $7.7 \pm 2.4$ & $8.0 \pm 2.4$ \\
\hline Surface area $\left(\mathrm{m}^{2}\right)$ & $0.36 \pm 0.2$ & $0.36 \pm 0.2$ & $0.37 \pm 0.2$ & $0.383 \pm 0.2$ & $0.383 \pm 0.2$ & $0.39 \pm 0.2$ & $0.4 \pm 0.2$ \\
\hline $\mathrm{Hb}(\mathrm{g} / \mathrm{dl})$ & $9.2 \pm 2.2$ & $8.6 \pm 1.8$ & $8.5 \pm 1.8$ & $8.35 \pm 1.7^{3}$ & $8.15 \pm 1.7$ & $7.8 \pm 1.6$ & $7.3 \pm 1.5$ \\
\hline $\mathrm{pH}$ & $7.42 \pm 0.03$ & $7.42 \pm 0.03$ & $7.42 \pm 0.03$ & $7.43 \pm 0.03$ & $7.44 \pm 0.03$ & $7.43 \pm 0.03$ & $7.44 \pm 0.03$ \\
\hline $\mathrm{PaCO}_{2}$ (torr) & $37 \pm 2$ & $39 \pm 3$ & $38 \pm 4$ & $37 \pm 3$ & $37 \pm 3$ & $37 \pm 3$ & $37 \pm 3$ \\
\hline $\mathrm{PaO}_{2}$ (torr) & $87 \pm 7$ & $75 \pm 9$ & $77 \pm 7$ & $82 \pm 6^{3}$ & $82 \pm 5$ & $86 \pm 6$ & $86 \pm 5$ \\
\hline \multicolumn{8}{|l|}{$\mathrm{O}_{2}$ consumption } \\
\hline$\left(\mathrm{ml} / \mathrm{min} / \mathrm{m}^{2}\right)$ & $210 \pm 52$ & $185 \pm 54$ & $191 \pm 42$ & $205 \pm 45$ & $208 \pm 39$ & $203 \pm 39$ & $196 \pm 48$ \\
\hline$(\mathrm{ml} / \mathrm{min} / \mathrm{kg})$ & $11.1 \pm 3.3$ & $9.95 \pm 2.9$ & $10.1 \pm 2.2$ & $10.4 \pm 2.3^{3}$ & $10.4 \pm 2.1$ & $10.3 \pm 2.1$ & $9.8 \pm 2.2$ \\
\hline \multicolumn{8}{|l|}{ Cardiac output } \\
\hline (liter $\left./ \mathrm{min} / \mathrm{m}^{2}\right)$ & $4.15 \pm 1.3$ & $3.96 \pm 1.1$ & $4.12 \pm 1.1$ & $4.48 \pm 1.1$ & $4.51 \pm 1.3$ & $4.46 \pm 1.2$ & $4.48 \pm 1.2$ \\
\hline$(\mathrm{ml} / \mathrm{min} / \mathrm{kg})$ & $246 \pm 69$ & $213 \pm 57$ & $218 \pm 58$ & $227 \pm 56^{3}$ & $230 \pm 65$ & $226 \pm 62$ & $224 \pm 60$ \\
\hline Heart rate (beats/min) & $174 \pm 30$ & $180 \pm 43$ & $176 \pm 36$ & $168 \pm 27$ & $166 \pm 24$ & $162 \pm 21$ & $158 \pm 20$ \\
\hline Mean aortic pressure $(\mathrm{mmHg})$ & $79 \pm 9$ & $74 \pm 11$ & $77 \pm 7$ & $80 \pm 7$ & $83 \pm 7$ & $83 \pm 6$ & $80 \pm 4$ \\
\hline $\begin{array}{l}\text { Mean pulmonary arterial pressure } \\
(\mathrm{mmHg})\end{array}$ & $17.0 \pm 4$ & $18.1 \pm 5.1$ & $16.2 \pm 3.4$ & $15.6 \pm 2.2$ & $15.7 \pm 2.2$ & $15.1 \pm 2$ & $14.5 \pm 1.3$ \\
\hline
\end{tabular}

${ }^{1}$ All values are mean \pm S.D.

${ }^{2}$ Preoperative values were only compared to the values on the third postoperative day.

${ }^{3} P<0.05$.

might occur as the result of thoracotomy. We also used Student's paired $t$ test to compare variables immediately before thoracotomy and on the third postoperative day, and to compare the effects of 15 min of hypoxia before and after thoracotomy. We used Student's unpaired $t$ test to compare the resting values and the \% changes after 15 min hypoxia in thoracotomized and nonthoracotomized age-matched lambs. We used a two-way analysis of variance with replication to compare the sequential changes during the $\mathrm{h}$ of hypoxia in the lambs before and after thoracotomy and in the thoracotomized and nonthoracotomized age-matched lambs.

\section{RESULTS}

Pre-and postthoracotomy resting values in the same lamb. Of the 15 lambs studied before and after thoracotomy, one died after the third postoperative day. Another was killed after the fifth postoperative day at the end of an experiment in which radionuclide labeled microspheres were used for flow measurements.

During the first two postoperative days, we found changes in most of the variables (Table 1). Only $\mathrm{pH}$ and $\mathrm{PaCO}_{2}$ were unchanged. Heart rate (range: $-27 \%$ to $+34 \%$ ) and aortic pressure (range: $-18 \%$ to $+13 \%$ ) changes were inconsistent, either increasing or decreasing; $\mathrm{O}_{2}$ consumption (range: $-28 \%$ to $+4 \%$ ) and cardiac output (range: $-33 \%$ to $+3 \%$ ) decreased, particularly on the first postoperative day.

On the third postoperative day (Table 1), only hemoglobin concentration and $\mathrm{PaO}_{2}$ were statistically different from control. Heart rate, pulmonary arterial pressure, cardiac output per $\mathrm{m}^{2}$, and $\mathrm{O}_{2}$ consumption per $\mathrm{m}^{2}$ returned to control; cardiac output and $\mathrm{O}_{2}$ consumption related to body weight were different from control but were not different from values corrected for the estimated increase of body weight over the 3-day period [calculated from the linear regression line obtained with the preoperative data (Fig. 1) and indicated by the open circles on Figure 2].

There was no significant difference in the slope or intercept of the linear regression lines obtained from the preoperative or the third postoperative day data either for $\mathrm{O}_{2}$ consumption, cardiac output, or heart rate (Fig. 1). This indicates that the thoracotomy did not affect normal changes of these variables with advancing age.

After the third postoperative day, the values followed the normal tendency of change with advancing age (Fig. 2), characterized by a fall in cardiac output per $\mathrm{kg}, \mathrm{O}_{2}$ consumption per $\mathrm{kg}$, heart

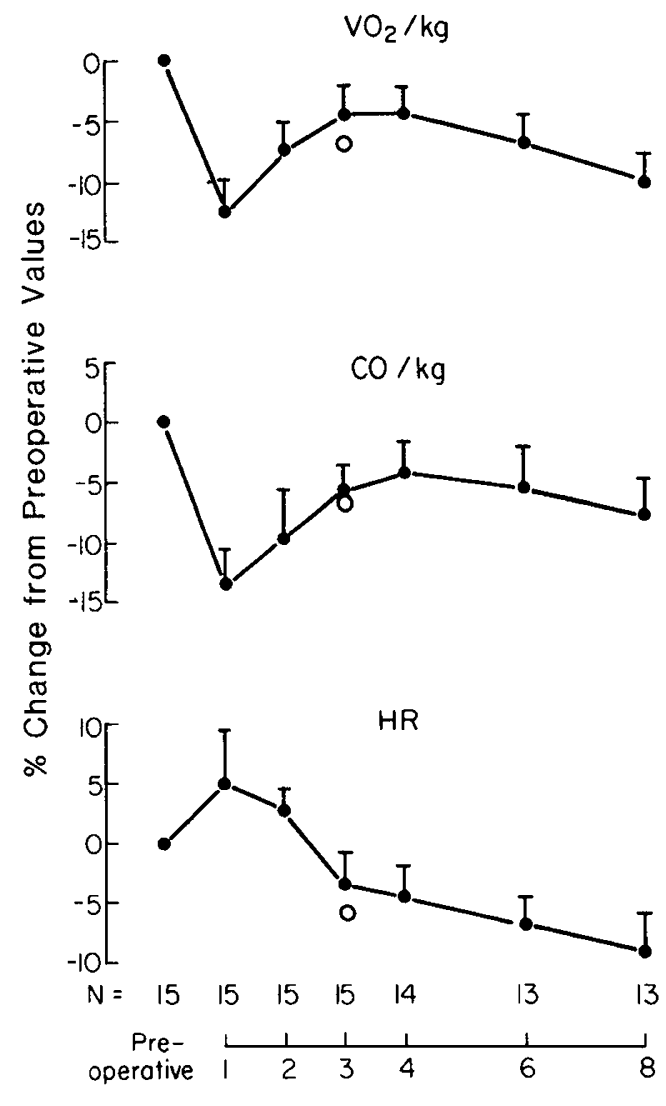

\section{Days after Thoracotomy}

Fig. 2. Percentage change from preoperative values of resting $\mathrm{O}_{2}$ consumption per min $\left(\mathrm{VO}_{2}\right)$, cardiac output $(\mathrm{CO})$, and heart rate (HR), measured after thoracotomy. The $\%$ change was calculated from values measured on each postoperative day and compared to the values measured before thoracotomy. Values are mean $\pm \mathrm{S}$.E. $\mathrm{N}=$ number of lambs, $\mathrm{O}=$ expected change with age (see text).

rate and pulmonary arterial pressure, and a slight increase in aortic pressure. The linear regression line obtained from the data of the sixth postoperative day was not different from the linear 
Table 2. Responses to hypoxia in four lambs before and on the third day after thoracotomy (Group II $)^{1}$

\begin{tabular}{|c|c|c|c|c|}
\hline & \multicolumn{2}{|c|}{ Before thoracotomy } & \multicolumn{2}{|c|}{ Third postoperative day } \\
\hline & Control & Hypoxia & Control & Hypoxia \\
\hline Age (days) & $6.25 \pm 4.7$ & & $15.0 \pm 4$ & \\
\hline Weight (kg) & $4.8 \pm 0.5$ & & $6.5 \pm 0.6$ & \\
\hline Surface area $\left(\mathrm{m}^{2}\right)$ & $0.30 \pm 0.08$ & & $0.354 \pm 0.09$ & \\
\hline $\mathrm{Hb}(\mathrm{g} / \mathrm{dl})$ & $8.1 \pm 2.7$ & & $8.15 \pm 2.7$ & \\
\hline $\mathrm{pH}$ & $7.41 \pm 0.03$ & $7.47 \pm 0.05$ & $7.42 \pm 0.03$ & $7.48 \pm 0.05$ \\
\hline $\mathrm{PaCO}_{2}$ (torr) & $36 \pm 1.7$ & $27.5 \pm 1.9$ & $37 \pm 1.1$ & $28 \pm 2.8$ \\
\hline $\mathrm{PaO}_{2}$ (torr) & $76 \pm 1.3$ & $28.5 \pm 6$ & $78 \pm 8$ & $31 \pm 5$ \\
\hline \multicolumn{5}{|l|}{$\mathrm{O}_{2}$ consumption } \\
\hline$\left(\mathrm{ml} / \mathrm{min} / \mathrm{m}^{2}\right)$ & $248 \pm 16$ & $226 \pm 6.4$ & $250 \pm 11$ & $215 \pm 16.5$ \\
\hline$(\mathrm{ml} / \mathrm{min} / \mathrm{kg})$ & $15.5 \pm 1$ & $14.1 \pm 0.4$ & $13.6 \pm 0.6$ & $11.7 \pm 0.9$ \\
\hline \multicolumn{5}{|l|}{ Cardiac output } \\
\hline$\left(\right.$ liter $\left./ \mathrm{min} / \mathrm{m}^{2}\right)$ & $5.216 \pm 0.88$ & $6.288 \pm 0.83$ & $4.866 \pm 1.2$ & $5,766 \pm 1.5$ \\
\hline$(\mathrm{ml} / \mathrm{min} / \mathrm{kg})$ & $326 \pm 55$ & $393 \pm 52$ & $265 \pm 64$ & $314 \pm 80$ \\
\hline Heart rate (beats/min) & $205 \pm 19$ & $305 \pm 40$ & $192 \pm 20$ & $276 \pm 25$ \\
\hline Mean aortic pressure $(\mathrm{mmHg})$ & $76 \pm 7$ & $78 \pm 8$ & $82 \pm 12$ & $84 \pm 3$ \\
\hline $\begin{array}{l}\text { Mean pulmonary arterial pressure } \\
(\mathrm{mmHg})\end{array}$ & $20 \pm 4$ & $35 \pm 5.8$ & $14.5 \pm 1$ & $23 \pm 2.4$ \\
\hline
\end{tabular}

${ }^{1}$ All values are mean \pm S.D. The values during hypoxia were measured after 15 min of exposure to $\mathrm{FIO}_{2}=0.09$.

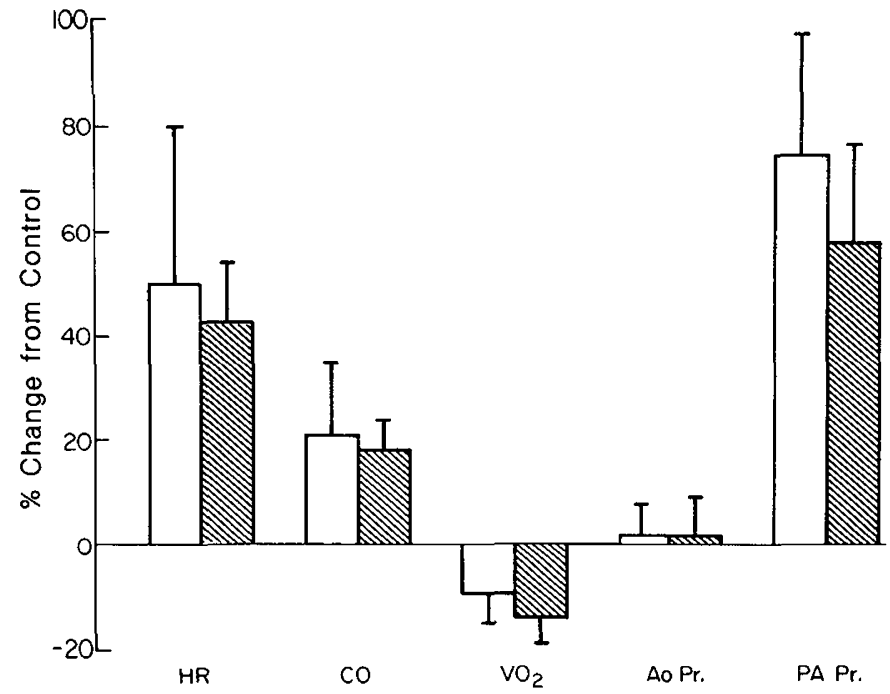

Fig. 3. Hypoxia induced $\%$ change from control of heart rate (HR), cardiac output $(\mathrm{CO}), \mathrm{O}_{2}$ consumption $\left(\mathrm{VO}_{2}\right)$, aortic mean pressure ( $\mathrm{Ao} \mathrm{Pr}$ ), and pulmonary arterial mean pressure (PA Pr) in the same lambs 3-4 days before $\square$ and on the third day after thoracotomy. Percentage change was calculated from values obtained after $15 \mathrm{~min}$ hypoxia $\left(\mathrm{FIO}_{2}=0.09\right)$ compared with those immediately before hypoxia. Values are mean \pm S.D. for four lambs.

regression lines obtained from the preoperative data, and data of the third postoperative day for either $\mathrm{O}_{2}$ consumption, cardiac output, or heart rate. Throughout the 8 days of the experiment, cardiac output and $\mathrm{O}_{2}$ consumption showed a parallel relationship both for the group and for each individual lamb.

Responses to hypoxia before and after thoracotomy in the same lamb. The differences in control values before and after thoracotomy are explained by normal growth (Table 2). The responses to hypoxia before and after thoracotomy were similar. None of the lambs became acidemic, despite a decrease of about $10 \%$ in $\mathrm{O}_{2}$ consumption. Although we did not measure ventilation or respiratory rates, there were no significant differences in blood gases, suggesting that the respiratory responses were similar. The maximum increases in heart rate and cardiac output were observed during the first $15 \mathrm{~min}$ after the onset of hypoxia, and the \% changes at $15 \mathrm{~min}$ hypoxia (Fig. 3) before and after thoracotomy were similar for heart rate, cardiac output, $\mathrm{O}_{2}$ consumption, and aortic and pulmonary arterial pressures. There also were no differences before and after thoracotomy in the values of the same five variables measured after 30,45 , and $60 \mathrm{~min}$ of hypoxia. Indicator dilution curves did not demonstrate significant right-toleft or left-to-right shunts in any of the animals.

Responses to hypoxia in age-matched lambs with or without thoracotomy. The control values were similar in the two groups (Table 3). As in the above comparison, there were no significant differences in the responses to hypoxia. The \% changes at the peak of the cardiovascular response (15 min hypoxia, Fig. 4) were similar for heart rate, cardiac output, $\mathrm{O}_{2}$ consumption, and aortic and pulmonary arterial pressure. Although $\mathrm{O}_{2}$ consumption in one of the thoracotomized lambs decreased by $30 \%$ and it became slightly acidemic, there were no differences for the group in the decrease in $\mathrm{O}_{2}$ consumption or in the increase of the other four variables after 30,45 , and 60 min hypoxia. No shunting was demonstrated by indicator dilution curves.

\section{DISCUSSION}

Thoracotomy is often necessary to make long-term continuous observations of cardiovascular function. To examine these cardiovascular functions during infancy, it is important to know whether thoracotomy itself affects the measurements. In adult animals, several wk can be allowed for recovery, but this is not possible in the neonate if one wishes to examine the rapid changes in cardiac output and other cardiovascular variables that normally follow birth.

We made daily measurements of $\mathrm{O}_{2}$ consumption, cardiac output, heart rate, aortic and pulmonary arterial pressures, and $\mathrm{pH}$ and blood gases in lambs following thoracotomy performed during the newborn period. We compared the responses to hypoxia on the third postoperative day with those before thoracotomy, and also with responses in age-matched lambs without thoracotomy.

Oxygen consumption, cardiac output, heart rate, and aortic and pulmonary arterial pressures returned to preoperative levels by the third postoperative day, and then followed the changes expected with advancing age. The changes associated with increasing age in our studies on unoperated lambs were similar to those reported by Lister and associates (6). The small fall in hemoglobin concentration probably was due to the lack of adequate replacement of blood lost during the thoracotomy. Arterial $\mathrm{Po}_{2}$ was slightly decreased, probably due to some degree of atelectasis or 
Table 3. Responses to hypoxia in lambs during the first wk after birth with or without thoracotomy (Group III) ${ }^{1}$

\begin{tabular}{|c|c|c|c|c|}
\hline & \multicolumn{2}{|c|}{ Without thoracotomy } & \multicolumn{2}{|c|}{ Third day after thoracotomy } \\
\hline & Control & Hypoxia & Control & Hypoxia \\
\hline $\mathbf{N}$ & 6 & & 6 & \\
\hline Age (days) & $3.75 \pm 1.5$ & & $5.15 \pm 1.7$ & \\
\hline Weight (kg) & $4.6 \pm 0.4$ & & $5.2 \pm 1.3$ & \\
\hline Surface area $\left(\mathrm{m}^{2}\right)$ & $0.29 \pm 0.07$ & & $0.31 \pm 0.14$ & \\
\hline $\mathrm{Hb}(\mathrm{g} / \mathrm{dl})$ & $9.5 \pm 2.8$ & & $9.9 \pm 1.9$ & \\
\hline $\mathrm{pH}$ & $7.41 \pm 0.03$ & $7.48 \pm .05$ & $7.40 \pm 0.02$ & $7.45 \pm 0.05$ \\
\hline $\mathrm{PaCO}_{2}$ (torr) & $35 \pm 3$ & $28 \pm 2$ & $38 \pm 2$ & $28 \pm 3$ \\
\hline $\mathrm{PaO}_{2}$ (torr) & $74 \pm 8$ & $25 \pm 4$ & $71 \pm 11$ & $26 \pm 5$ \\
\hline \multicolumn{5}{|l|}{$\mathrm{O}_{2}$ consumption } \\
\hline$\left(\mathrm{ml} / \mathrm{min} / \mathrm{m}^{2}\right)$ & $244 \pm 19$ & $228 \pm 21$ & $231 \pm 40$ & $203 \pm 35$ \\
\hline$(\mathrm{ml} / \mathrm{min} / \mathrm{kg})$ & $15.4 \pm 1.2$ & $14.4 \pm 1.3$ & $13.8 \pm 2.4$ & $12 . I \pm 2.1$ \\
\hline \multicolumn{5}{|l|}{ Cardiac output } \\
\hline$\left(\right.$ liter $\left./ \mathrm{min} / \mathrm{m}^{2}\right)$ & $4.679 \pm 0.73$ & $5.615 \pm 0.619$ & $4.663 \pm 1.02$ & $5.870 \pm 0.956$ \\
\hline$(\mathrm{ml} / \mathrm{min} / \mathrm{kg})$ & $295 \pm 46$ & $354 \pm 39$ & $278 \pm 61$ & $350 \pm 57$ \\
\hline Heart rate (beats/min) & $195 \pm 10$ & $295 \pm 17$ & $182 \pm 34$ & $275 \pm 43$ \\
\hline Mean aortic pressure $(\mathrm{mmHg})$ & $72 \pm 5$ & $74 \pm 7$ & $71 \pm 6$ & $75 \pm 6$ \\
\hline $\begin{array}{l}\text { Mean pulmonary arterial pressure } \\
(\mathrm{mmHg})\end{array}$ & $24 \pm 5$ & $38 \pm 5$ & $19 \pm 2$ & $29 \pm 14$ \\
\hline
\end{tabular}

' All values are mean \pm S.D. The values during hypoxia were measured after 15 min of exposure to $\mathrm{FIO}_{2}=0.09$.

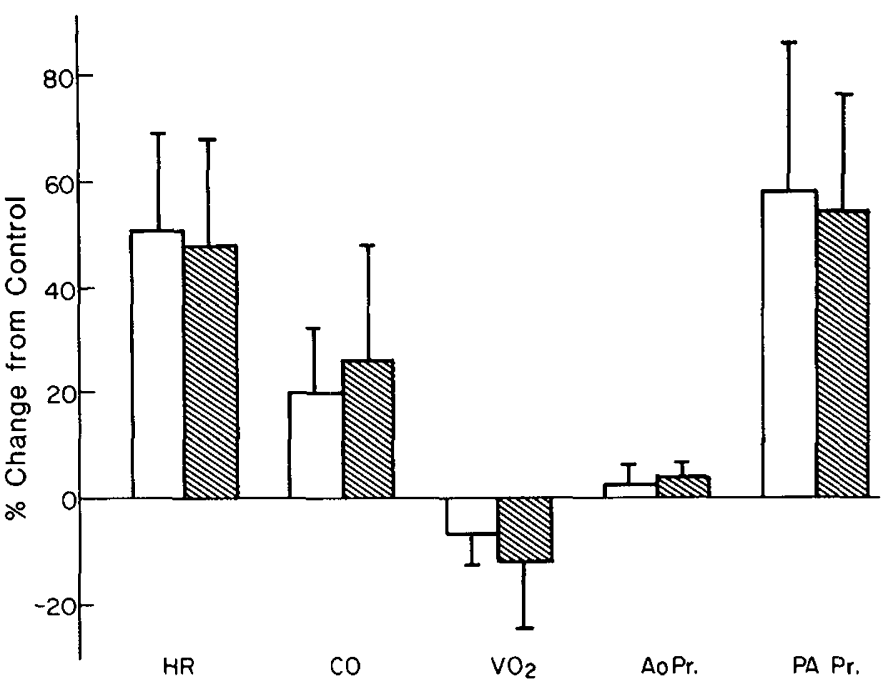

Fig. 4. Hypoxia induced $\%$ change from control of heart rate (HR), cardiac output $(\mathrm{CO}), \mathrm{O}_{2}$ consumption $\left(\mathrm{VO}_{2}\right)$, aortic mean pressure (Ao $\mathrm{Pr}$ ), and pulmonary arterial mean pressure (PA Pr) in age-matched lambs with $\square$ or without $\mathbb{\mathbb { N }}$ thoracotomy. Percentage change was calculated from values obtained after $15 \mathrm{~min}$ hypoxia $\left(\mathrm{FIO}_{2}=0.09\right)$ compared with those immediately before hypoxia. Values are mean \pm S.D. for six lambs.

pleural effusion, but it did not affect arterial oxygen saturation significantly. The parallel changes in cardiac output and oxygen consumption for each lamb indicated that the arteriovenous difference was constant during the 8-day period of study.

We studied the response to stress in order to assess cardiovascular reserve after surgery. In studies with thoracotomized lambs, Klopfenstein and Rudolph (3) observed that the increases in heart rate and cardiac output associated with rapid volume loading by intravenous infusion of $20 \mathrm{ml} / \mathrm{min} / \mathrm{kg}^{-1}$ for 2 min were similar on the third, sixth, or ninth postoperative day. In that study there was no comparison with responses to volume loading before or without thoracotomy that would have allowed for the evaluation of the effect of the thoracotomy. Their findings, at least, suggest that there was no further recovery from the thoracotomy after the third up to the ninth postoperative day. The studies of hypoxia in our lambs also suggest that cardiovascular function had recovered by the third postoperative day. The similar responses to hypoxia before thoracotomy and on the third postoperative day in the same lambs are very suggestive of good recovery, unless there was an age-related difference in the response to hypoxia that masked the changes that might have been caused by the thoracotomy. The similar responses to hypoxia in age-matched newborn lambs with and without thoracotomy excludes this latter possibility, and further shows that when thoracotomy was performed in young lambs, there was recovery by the third postoperative day.

The increase in heart rate and decrease in aortic pressure that Woods et al. (8) observed for 2 wk after thoracotomy in newborn lambs are difficult to explain. It is possible that, because they dissected the region of the ductus arteriosus extensively, the changes were secondary to irritation of the sympathetic nerves.

In this study we did not evaluate indices of myocardial function, such as contractility or pressure volume curves. Because of the pericardiotomy, there may have been a shift in the diastolic pressure-volume relationship (2) that our measurements could not detect. Although the values at rest and the response to hypoxia $\left(\mathrm{FIO}_{2}, 0.09\right)$ were normal, it is possible that other kinds of stresses, such as pressure loading on the ventricle, would reveal differences that did not appear in our study. Nevertheless, we believe that for studies of general cardiovascular responses, the preparation we have described can be used reliably because it does not disturb the basic cardiovascular and respiratory functions beyond the third day after surgery.

\section{REFERENCES AND NOTES}

1. Fisher, D. J., Heymann, M. A., and Rudolph, A. M.: Myocardial oxygen and carbohydrate consumption in fetal lambs in utero and in adult sheep. Am. J. Physiol., 238: H399 (1980).

2. Glantz, S. A., Misbach, G. A., Moores, W. Y., Mathey, D. G., Lekven, L., Parmley, W. W., and Tyberg, J. V.: The pericardium substantially affects the left ventricular diastolic pressure volume relationship in the dog. Circ. Res., 42: 433 (1978)

3. Klopfenstein, H. S. and Rudolph, A. M.: Postnatal changes in the circulation and response to volume loading in sheep. Circ. Res., 42: 839 (1978).

4. Kuipers, J. R. G., Sidi, D., Heymann, M. A., and Rudolph, A. M.: Comparison of methods of measuring cardiac output in newborn lambs. Pediatr. Res., in press.

5. Lister, G., Hoffman, J. I. E., and Rudolph, A. M.: Oxygen uptake in infants and children: a simple method for measurement. Pediatrics, 53: 656 (1974).

6. Lister, G.. Walter, T. K.. Versmold, H. T., Dallman, P. R., and Rudolph, A. M.: Oxygen delivery in lambs: cardiovascular and hematologic development. Am. J. Physiol., 237: H668 (1979).

7. Ritzman, E. G. and Colovos, N. F.: Surface area of sheep. N. Hampshire Agric. 
Exp. Sta. Circ., 32:1 (1930).

8. Woods, J. R., Jr., Dandavino, A., Brinkman, C. R., III, and Assali, N. S.: Cardiac output changes during neonatal growth. Am. J. Physiol., 234: H520 (1978).

9. The present address of Dr. Daniel Sidi: Service de Cardiologie Infantile, Hôpital Necker-Enfants Malades, Rue Sevrès, Paris 75015, France.

10. The present address of Dr. Jaap R. G. Kuipers: University of Groningen, Academic Hospital, Department of Pediatric Cardiology, Oostersingel 59, 9713 EZ, Groningen, The Netherlands.

11. The authors wish to gratefully acknowledge the assistance of Ms. Susan Axelrod and Ms. Christine Roman.

12. Requests for reprints should be addressed to: M.A. Heymann, M.D., 1403-HSE, University of California, San Francisco, California 94143.

13. This research was supported by U.S. Public Health Service grants HL23681 \& HL24056, and a grant awarded by the French government and the Francis North Foundation (D.S.) and a NATO grant awarded by the Organization for the Advancement of Pure Research-Z.W.O. (J.R.G.K.).

14. Received for publication July 27, 1981

15. Accepted for publication February 11, 1982.

\section{ANNOUNCEMENT}

The three-day course, first in Europe, will include plenary sessions, lectures and concomitant workshops covering a schedule of 50 hours. On the 4th day, October 17, there will be a round table open also to different staffs and families. This Course is designed primarily for pediatricians, geneticists, cytogeneticists, obstetricians, biologists and other scientists involved in Birth Defects. Active participation of the registrants will be encouraged in the workshops and by question-and-answers panels after lectures.

There will be ample opportunity for informal discussions. Poster sessions will be available.

The tuition fee, $\$ 130$, includes also 3 lunches and one dinner-dance in the Chianti countryside. Students and research fellows, $\$ 70$.

The Guest Faculty will consist of distinguished speakers from different countries: Cohen M. M. (Canada), Der Kaloustian V. M. (Lebanon), Emery A. (Scotland), Galjaard H. (Netherlands), German J. L. III (U.S.A.), Gorlin R. J. (U.S.A.), Hall J. G. (Canada), Harper P. S. (U.K.), Klein D. (Switzerland), Laurence K. M. (U.K.), Lindsten J. (Sweden), Mikkelsen M. (Denmark), Milunsky A. (U.S.A.), Motulsky A. G. (U.S.A.), Opitz J. M. (U.S.A.), Polani P. (U.K.), Rehder H. (Germany), Réthoré O. (Francia), Rimoin D. L. (U.S.A.), Sperling K. (Germany), Spranger J. (Germany), Weatherall J. A. C. (U.K.), Williamson R. (U.K.), Wolf U. (Germany).

Chairman:

M. FRACCARO, University of Pavia

Co chairmen:

A. FOIS, University of Siena

M. GIUSTI, Children Hospital Florence
Scientific Secretary:

M. L. GIOVANNUCCI UZIELLI

Human Genetics Service

Institute of Pediatrics

University of Florence

For further information contact:

Organizing Secretariat

Identification Genetic Syndromes

Ospedale Pediatrico A. Meyer

Via L. Giordano, 13

50132 Florence-Italy

Phone 055/57.59.53 